\title{
Karl Emil Franzos: um literato entre a Europa Central e a SEMI-Ásia
}

Luis S. Krausz'

ABstract: Karl Emil Franzos' (1848-1904) oeuvre represents a caesura within the literary tradition known as Ghettoliteratur and marks the establishment of clearly drawn borders separating the world of Eastern European Jewry from the so-called civilized Europe. The gradual penetration of 19th. Century humanistic ideas - in particular, those of the philosopher Moses Mendelssohn - in the world of traditional Jews has led to a deep conflict within European Jewry in the 19th. Century, and Franzos is one of those litterati who voices this conflict, clearly defending the modern and emancipated part of the community, and setting it against the religious-traditional sector.

It would be no exaggeration to say that this conflict is the main subject of his oeuvre, and that it gives voice to some paradigms which have become increasingly important both for the way emancipated Jews saw themselves and for the anti-semitic discourse which has gained momentum in late $19^{\text {th }}$ Century Germany and Austria.

By identifying traditional Jews with Asian barbarians, Franzos applies the terms of the mind of Enlightenment and plays a crucial role in the establishment of two complementary Jewish-European identities: that of the Ostjude (Eastern Jew) and that of the Westjude (Western Jew).

KEYWORDs: Ethnocentrism, Jewish literature, Jewish iluminism.

1 Doutor em Literatura e Cultura Judaicas pela Universidade de São Paulo, pós-doutorando da Fapesp junto ao Departamento de Letras Orientais da FFLCH/USP. Autor de Rituais Crepusculares: Joseph Roth e a nostalgia Austro-judaica, Edusp, São Paulo, 2007. 
Karl Emil Franzos (1848-1904) é o mais conhecido, prolífico e influente autor da segunda geração da chamada Ghettoliteratur, um gênero que floresceu no universo cultural alemão do século XIX, e que tem por tema central o confronto entre a tradição judaica e a modernidade, numa época em que se ensaiava a integração social dos judeus, até então confinados em guetos. Em seus romances, novelas e contos Franzos retratou, de maneira enfática, crítica e marcada, de um lado, pelos princípios do determinismo e do naturalismo na literatura, e de outro por sua ligação incondicional com os princípios e padrões da cultura alemã do século XIX, o universo humano de sua Galícia natal: sua visão acerca dos judeus tradicionalistas, que viviam nessa região, tomada da Polônia e anexada pelo Império Austro-Húngaro, em 1772, foi crucial para a cristalização da imagem desse grupo étnico na imaginação literária de seu tempo. Incisivo, implacável em sua cruzada em prol dos valores do iluminismo e da Bildung, isto é, dos ideais da ilustração alemã de molde romântico, Franzos foi também autor de um sem-número de Feuilletons, publicados na Neue Freie Presse e na Frankfurter Zeitung, os dois mais influentes jornais do mundo de língua alemã de seu tempo, e também responsável pela criação de um subgênero singular na Ghettoliteratur: seus chamados Kulturbilder, narrativas que têm as dimensões de um conto, porém uma abordagem jornalístico-descritiva - e não dramática.

Filho de uma família modernizada - seu pai era médico e em sua casa $o$ alemão era a língua do quotidiano -, Franzos nasceu em Czortkow, na Galícia austro-húngara, e descendia de uma família de origem sefardita, que emigrara da França, de onde seu sobrenome: Franzos, em alemão, significa francês, e esse nome foi concedido a seu avô sob o governo de José II, que atribuiu nomes alemães a todos os judeus do Império Austro-Húngaro. Os sefarditas, sègundo o próprio Franzos, que desde a infância sentia-se, de certa forma, um estranho entre os judeus de Czortkow, a quem cedo aprendeu a mirar com distanciamento e ceticismo, seriam "um ramo distinto do judaísmo, com um forte comprometimento com a tradição, mas, ao mesmo tempo, muito abertos para a cultura da modernidade, e sobretudo para as ciências". O bisavô de Franzos era um fabricante de velas que, no século XVIII, estudara medicina em Utrecht, Holanda. Seu avô, aos quarenta anos de idade, começou a estudar direito em 
Lemberg (hoje L'vov, Ucrânia), à época, com sua universidade, um dos centros de cultura alemã que foram implantados na Galícia pelos monarcas habsburgos, e foi um seguidor entusiasmado das ideias de Moses Mendelssohn, o arauto do iluminismo e da emancipação judaicas.

Franzos empenhou-se no esforço lançado por Mendelssohn no sentido da conquista de direitos civis pelos judeus, e apoiou o estabelecimento de instituições de ensino alemãs para os judeus de Czortkow e de outras cidades na Galícia, cujo objetivo era, ostensivamente, o de integrar os judeus à modernidade laica que, pouco a pouco, se estabelecia em território austro-húngaro. Essas instituições, que começaram a surgir na região já desde o início do século XIX, seguiam os valores e o pensamento da Haskalá e objetivavam a criação de uma nova identidade judaica, passível de integração no cenário político e econômico do liberalismo josefinista. Seu lema, assim, era "educação para os judeus", e esta educação trazia implícita a ideia de uma ruptura radical com as tradições religiosas que vinham moldando a vida judaica do Leste europeu havia séculos, e que passavam a ser vistas como retrógradas e obsoletas. O sentido do estabelecimento dessas escolas deve ser buscado no contexto mais amplo da política de integração dos judeus à cultura alemã, promovida já pelo Imperador José II, pouco tempo depois da conquista da Galícia, tomada da Polônia em 1772, e que tinha como objetivo, também, a consolidação da presença imperial nessa região.

Heinrich Franzos, o pai de Karl Emil, era, igualmente, um homem empenhado na integração ao universo da cultura alemã. Seguidor convicto dos princípios da Haskalá alemã, ele repetia, sempre, a seu filho: "Tua nacionalidade não é polonesa, nem rutena (ucraniana) nem judaica - você é alemão" (FRANZOS, 1970, p. 162), “e enquanto você não conhecer bem o alemão, jamais poderá se considerar uma pessoa culta". Heinrich Franzos faleceu quando seu filho tinha a idade de dez anos, e foi sempre uma figura idealizada por seu filho, assim como o foram seus princípios e suas ideias. Por sua origem familiar, portanto, bem como por seu interesse por uma cultura que ainda era vista como "estranha" por vastos setores da sociedade judaica de Czortkow, predominantemente tradicionalista e profundamente influenciada pelas doutrinas do pietismo judaico ou hassidismo, Franzos estava desde cedo habilitado a lançar um olhar crítico e impiedoso sobre seu mundo de origem. 
Czortkow era, à época da infância de Franzos, um importante centro do hassidismo e sede de uma corte rabínica que atraía crentes vindos de cidades distantes em busca de bênçãos e de curas milagrosas. O pai de Franzos, como Bezirksartzt (médico de distrito), era também uma espécie de concorrente do famoso czortkower Rebbe - o rabino era, até então, a instância máxima em todas as questões, para os judeus religiosos. Sua presença na cidade, assim, era também um símbolo da introdução, patrocinada pelo Estado habsburgo, de uma mentalidade científica numa região em que predominavam as ideias religiosas, inclusive a respeito da origem das doenças e de suas curas.

As opiniões liberais e a visão de mundo científica de Heinrich Franzos o indispuseram tanto com a nobreza polonesa da cidade quanto com o setor religioso da comunidade judaica, e essas antipatias certamente faziam-se perceber na casa da família: os reacionários fidalgos poloneses, cheios de preconceitos, indolentes e perdulários, são, ao lado dos judeus supersticiosos e obscurantistas, personagens recorrentes na sua multifacetada obra de ficção que, desde sempre, mostra um engajamento ativo na defesa do avanço da cultura germânica no leste do Império Austro-Húngaro.

$\mathrm{O}$ ambiente em que Franzos nasceu, assim, bem como os conflitos que cercavam a existência de sua família em Czortkow, está presente na totalidade de uma obra literária cujos personagens são, sempre, retratados como produtos de seu meio, e sua literatura é integralmente plasmada sobre o choque entre culturas e mentalidades que sacudiu o judaísmo da Europa Central no século XIX.

Pouco depois da morte do pai, e com o objetivo específico de propiciar a Karl mudou-se para Czernowitz, então uma espécie de ilha de Bildung de molde alemão no leste do Império, e lá ele passou a frequentar o Gymnasium de língua alemã, do qual foi aluno entre 1859 e 1867. Czernowitz era o centro de uma região marcada por uma rica diversidade étnica e cultural, que lhe parecia estimulante, mas que ele aprendeu, desde sempre, a julgar segundo os critérios e parâmetros da cultura alemã. A burguesia local, em ascensão, empenhava-se em demonstrar que não vivia numa terra de ursos, e sim numa ilha de cultura, estreitamente vinculada à Mitteleuropa e à capital habsburga, da qual se via 
como uma colônia e um posto avançado. Ao mesmo tempo, a prosperidade crescente da burguesia de Czernowitz e a harmonia em que conviviam os seus povos eram vistas, por Franzos e por seus contemporâneos, como os benefícios diretos e palpáveis da implantação da cultura alemã, em contraposição às tradições religiosas retrógradas que dominavam aquela parte da Europa até então, cujo caráter bárbaro e "asiático" Franzos destaca, de maneira recorrente, em sua literatura. A Alemanha, assim, torna-se, para ele, sinônimo da cultura e desempenha o papel de portadora de salvação para um Leste dominado pelas trevas e pela superstição.

A dimensão política da germanização dos judeus da Galícia é um aspecto fundamental do fenômeno de transformação cultural de que Franzos dá testemunho. A região era habitada por três grupos étnicos principais: os rutenos (ou ucranianos), cristãos ortodoxos, os poloneses católicos e os judeus. $\mathrm{Na}$ medida em que esse terceiro grupo sempre fora marginalizado pelos outros dois, e sujeito a uma série de restrições econômicas e políticas fundamentadas em conceitos religiosos, a germanização dessa população da fronteira oriental do Império e sua integração nas instituições monárquicas, como cidadãos com igualdade de direitos, eram também uma maneira afirmativa de garantir a presença do poder habsburgo na região.

O crescimento da presença do Estado por meio de instituições destinadas a ampliar o alcance da nacionalidade alemã sobre o território habsburgo, assim, deu-se, também, por meio da expansão do uso da língua alemã nessas províncias do Leste e filiação, a essa língua e à sua cultura, dos novos cidadãos representava a constituição de novos poderes políticos e culturais no Leste, dos quais Franzos é um aliado incondicional. A germanização judaica representava, também, uma ameaça clara e crescente aos poderes judaicos clericais então constituídos. A Galícia e a Bucovina, mas também a região do assentamento judaico, para além das fronteiras que separavam o Império habsburgo da Rússia, eram uma região repleta de Wunderrabbis (rabis milagrosos), que gozavam de enorme prestígio, e cujas cortes chegavam a rivalizar, em esplendor, com as dos nobres cristãos. Esses sacerdotes eram autoridades em todos os setores da vida - do espiritual ao da implementação da justiça, da educação à saúde. Suas doutrinas, julgamentos, lições e curas milagrosas constituíam o alfa e o ômega 
da vida social e familiar dos judeus tradicionalistas, de maneira que eles se afiguravam, também, como ameaças à presença de um Estado de feições modernas nessa região.

Seguidor do realismo literário, Franzos retratou, portanto, um mundo judaico em transição. A concepção de uma providência divina que se manifesta diretamente na vida dos personagens; que é o cerne de uma tradição que vê a esfera mundana como a simples contrapartida de outra esfera, impalpável, porém cujos sinais são claramente sentidos, perpassa as obras de pioneiros da Ghettoliteratur. $\mathrm{O}$ legado judaico, que esses autores desejam transmitir às novas gerações, e que aparece como um tesouro cultivado, lapidado e preservado ao longo dos séculos, em Franzos torna-se um conjunto repelente de superstições privadas de sentido e destinadas ao desaparecimento ante o avanço da Bildung alemã e de um novo humanismo. Não há, em sua obra, aqueles momentos de empatia e de reverência, de fineza de sentimentos e respeito à fé ancestral que iluminam os textos fundantes da Ghettoliteratur. Os judeus tradicionalistas retratados por Franzos não aparecem como os portadores de uma Humanitas genuína, nem tampoụco como donos de uma voz própria. De uma maneira perversamente oitocentista, e não desprovida de perigos, eles se tornam objetos que se oferecem a uma investigação e a um julgamento em que não lhes é dado direito de voz, de maneira que sofrem uma espécie de privação - ainda que só na esfera literária - de sua própria condição de seres humanos.

A literatura de Franzos, assim, representa uma ruptura total com a tradição judaica leste-europeia, e assinala a dissociação e o estabelecimento de fronteiras claras que passam a separar, em seu imaginário, o Leste do Oeste, 0 gueto da modernidade, a barbárie e a civilização. O conflito aparentemente irresolvível entre os setores religioso e secular da sociedade judaica da Europa Central penetra em sua obra em toda sua extensão, cristalizando barreiras que parecem intransponíveis, estabelecendo maneiras estereotipadas de ver e de julgar a realidade e erguendo, de maneira aberta e direta, a bandeira da germanização e da modernização dos costumes como solução para a miséria espiritual e a desolação material da Galícia. Os preconceitos, e também a perseguição, não raro violenta, entre fações judaicas, de uma parte, e entre antissemitas $\mathrm{e}$ judeus, de outra, estão na ordem do dia de uma literatura que tem algo de 
panfletário, ambientada sempre naquele território a que ele se refere, com ironia, de Halb-Asien, isto é, "Semi-Ásia”.

O termo Halb-Asien encontra correspondência na ideia de Honoré de Balzac, expressa na Comédie Humaine, que resume a perspectiva europeia "civilizada" sobre os países do Leste: "Os habitantes da Ucrânia, da Rússia, das planícies do Danúbio, em resumo, os povos eslavos, são uma ligação entre a Europa e a Ásia, entre a civilização e a barbárie” (WOLFF, 1994, p. 13). Não por acaso, em seus Kulturbilder Franzos reiteradamente se dirige a seus leitores como "Ihr Europäer", "vós, europeus", ao mesmo tempo em que se propõe a descrever as circunstâncias de sua pitoresca, mas também assustadora, terrível, e sempre estereotipada Halb-Asien. Assim, a Comédie Humaine de Franzos - uma obra que, como a de Balzac, caracteriza-se por uma coesão e uma continuidade que perpassa todas as suas partes - tem como assunto central os hábitos escandalosos de seus personagens semiasiáticos, esses moradores da Polackei e do Bärenland, como ele se refere, de maneira derrogatória, às terras em que veio ao mundo.

A identificação da Ásia - e por conseguinte do Oriente ou do Leste - como o território da barbárie, da selvageria, da ausência de discernimento, do desperdício e da ignorância, isto é, como o absoluto contrapolo da "civilização", que se afigura na obra de Franzos ecoa uma concepção e um dos temas centrais dos iluministas a respeito do Leste e da polaridade que se cristalizou, na mentalidade europeia, ao longo do século XIX, entre Ocidente e Oriente. O iluminismo, com seus centros intelectuais na Europa Ocidental, cultivou e apropriou-se da noção de "civilização", um neologismo do século XVIII - e a "civilização" descobriu sua contrapartida, no mesmo continente em que surgiu, nos países sombrios e atrasados que ficam para além de uma fronteira cujos contornos fluidos percorrem, ora mais para o leste, ora mais para o oeste, toda aquela região que, vista de uma perspectiva mais otimista, também poderia afigurar-se como a Mitteleuropa. (cf. WOLFF, 1994, p. 4)

É essa mesma polaridade que fundamenta a criação das imagens especulares e estereotipadas do judeu tradicionalista e do judeu modernizado, no universo da literatura judaica de língua alemã, cuja cristalização parece apoiar-se, 
de maneira significativa, sobre os retratos e descrições criados por Franzos. Ele aponta, sempre, para as contradições e os absurdos das formas de organização - ou desorganização - social de sua terra natal, ecoando aquela tradição das letras europeias que se estabelece a partir do final do século XVIII, e que serviu, inclusive, como uma espécie de justificativa moral para a anexação de partes da Polônia à Alemanha e à Áustria, em 1772, dando à ocupação uma espécie de valor redentor, na medida em que a mesma significaria a implementação da civilização no universo da barbárie, triunfo do esclarecimento sobre as trevas, o avanço da cultura sobre a ignorância.

A contradição e o paradoxo estão sempre presentes nas descrições de Franzos, que contrapõe a realidade galiciana, com sua desordem e seu caráter aleatório, às ideias "civilizadas" a respeito da sociedade, da política, da educação, do papel dos homens e das mulheres. A anarquia que reina na vida quotidiana, ali, contrapõe-se, assim, ao rigoroso sentido de hierarquia que é a essência da mentalidade germânica e habsburga em particular; o caráter aleatório e errático dos acontecimentos é o inverso do sentido de disciplina que é fundamental à ética germânica, e também ao capitalismo industrial, à época em grande expansão, e a violência, que perpassa todas as esferas da vida, choca-se, frontalmente, com um conceito de civilidade que tem por fundamento o respeito aos direitos dos cidadãos.

O conceito de "atraso", de regressão a um estágio anterior da história da humanidade, de estagnação e de incapacidade esteve associado na mentalidade europeia ao Leste desde o século XVIII. Em seu estudo a respeito da invenção da Europa Oriental na imaginação iluminista, Larry Wolff cita diferentes passagens de livros de autores viajantes, como o Conde Ségur, embaixador francês na corte russa, o viajante inglês William Coxe ou o célebre Giaccomo Casanova. Esses autores, que a princípio parecem ter pouco em comum entre si, são unânimes ao darem voz a seu espanto ante as circunstâncias com que se deparam nessas terras:

O conde de Ségur, ao entrar na Europa do Leste em seu caminho em direção a São Petersburgo, no inverno de 1784-85, para servir como embaixador francês na corte de Catarina a Grande, ao passar da Prússia para a Polônia, estava bem 
consciente de estar cruzando uma fronteira muito significativa: Ele sentia que "havia deixado a Europa inteiramente", e além disto, que "recuara dez séculos". (WOLFF, 1994, p. 6) ${ }^{2}$

Wolff cita as palavras do próprio conde, que descreve, com sarcasmo, as curiosidades de uma Polônia repleta de contradições e de paradoxos, em que os parâmetros da "civilização" são constantemente invertidos. Ele fala de um país verde, mas de paisagem triste, cuja população escassa é, no entanto, miserável e escravizada, e cujos casebres são pouco mais do que toscas choupanas de selvagens. "Tudo nos leva a pensar que voltamos dez séculos no tempo, e que nos encontramos em meio às hordas de hunos, cítios, eslavos e sármatos. A riqueza de grãos contrasta com a falta de dinheiro; a paixão pela guerra com a total ausência de disciplina”, escreve, o conde, cuja viagem tem início logo após a Revolução Francesa.

William Coxe narra um percurso pela Galícia austro-húngara, em 1778: "as estradas eram poucas e os vilarejos de uma miséria indescritível: choupanas de madeira pareciam repletas de sujeira e de pobreza, como tudo o mais". As únicas hospedarias, pertencentes a judeus, eram totalmente destituídas de móveis são descritas por ele como "receptáculos de imundície e de penúria". À medida que ele aprofunda sua incursão por esse território desconhecido, cruzando a Galícia austro-húngara em direção a São Petersburgo, as idiossincrasias da população, escravizada por uma nobreza perdulária, a abjeção e a melancolia intensificam-se. A presença dos judeus, que segundo a descrição de Coxe "aparecem o tempo todo", é outra característica dessa região exótica. Eles lhe parecem "extraordinariamente industriosos", em contraposição à indolência e, sobretudo, ao alcoolismo, que a ela conduz, e que é associado pelos viajantes dos séculos XVII e XIX, de um modo geral, aos poloneses, russos e ucranianos. "Peça um intérprete, e eles trarão um judeu. Entre numa estalagem e

2 WOLFF, 1994, p. 6: "When the count de Ségur, entering Eastern Europe on his way to St. Petersburg in the winter of 1784-85 to serve as French ambassador to the court of Catherine the Great, passed from Prussia into Poland, he was powerfully conscious of crossing an extremely significant border. He felt that he had "left Europe entirely", and furthermore had "moved back ten centuries". 
seu proprietário será um judeu. Se você precisa de cavalos, um judeu os arranjará e um judeu os conduzirá". Ele diz, ainda, que “os judeus estimularam todo o comércio do país".

Ao mesmo tempo, a violência, a superstição, a irracionalidade e a ausência de controle sobre as paixões são as características que a mente do iluminismo associa à paisagem humana da Europa do Leste. Giaccomo Casanova (WOLFF, 1994, p. 6), destaca os ciúmes doentios de uma jovem russa, que ele comprara como escrava de sua própria família por 100 rublos, bem como sua obsessão por ler a sorte nas cartas - talvez a mais radical contraposição à maneira iluminista de compreender o mundo.

A escravidão, particularmente com objetivos sexuais, é outra das características ubíquas, no olhar desses viajantes, nesse território obscuro, cuja população está sujeita a um sistema estagnado de relações sociais delimitado pelo despotismo absoluto, de um lado, e pela absoluta sujeição, de outro. Ségur escreve que "a verdadeira razão para a lentidão da civilização é a escravidão: 0 servo, desprovido de qualquer orgulho, privado de amor próprio e rebaixado quase que ao nível da animalidade, só tem necessidades físicas e limitadas. Seu desejo não vai além daquilo que é estritamente necessário para sustentar sua triste existência, e pagar os tributos que seu senhor lhe impôs".

A resignação e o fatalismo são as características mais revoltantes do universo psicológico leste-europeu aos olhos de um Ocidente que se propõe a transformar a condição humana com o ímpeto fáustico e titânico do iluminismo, alçando o homem, por meio da aplicação de uma racionalidade pura e do estabelecimento de categorias inabaláveis, respaldadas pela objetividade científica, a uma posição orgulhosa, de poder e de independência. As condições feudais - psicológicas, sociais e econômicas - encontradas por esses viajantes em suas incursões por essa outra Europa são vistas como decorrência da ignorância que leva à estagnação.

Voltaire descreve a Rússia em termos de civilização e barbárie que têm por pressuposto o mesmo colonialismo cultural que parece ter justificado, em termos morais, a destruição das culturas americanas pré-colombianas pelos invasores europeus: "Os moscovitas eram menos civilizados do que os mexicanos quando estes foram descobertos por Cortez. Todos nasceram como 
escravos de senhores tão bárbaros quanto eles mesmos, estagnados em sua ignorância, carentes de todas as artes e também insensíveis a essas carências, o que destruía, neles, toda indústria" (Cf. WOLFF, 1994, p.9). Os viajantes destacam, também, que os servos, tão logo atingem a puberdade, são casados, à força, por seus senhores, de maneira a gerar novos servos, "cujos corações nunca foram humanizadcs pelo afeto de pais que não se amam": a barbaridade do Leste, transmitida de geração em geração, decorre da perpetuação de uma tirania que se estende sobre todas as esferas da existência e da inexistência da noção de liberdade humana, talvez o mais caro dos conceitos formulados pela mentalidade iluminista. Ao mesmo tempo, o caráter retrógrado da região é o que justifica, na mentalidade ocidental, a autoridade e a dominação por parte dos "civilizados" - como, de resto, nas outras partes do mundo que foram sendo gradativamente ocupadas pela expansão colonial: domar a selvageria torna-se, assim, uma das tarefas nobres da civilização.

A desorientação e os desafios que a realidade leste-europeia propõe aos viajantes ocidentais, por seu turno, põem em xeque os conceitos fundamentais da civilização ocidental: a incapacidade de raciocinar e a própria submissão da razão às superstições bastam para desqualificar as formas de vida de uma população vista como semisselvagem, arcaica, mergulhada no obscurantismo. A bandeira da civilização e o confronto desta civilização com o Leste são, assim, temas cruciais dessa literatura de viagem, que ajudou a plasmar o entendimento ocidental daquela estranha e descomedida região que se estende a partir da Mitteleuropa, e que se torna cada vez mais indecifrável à medida que se viaja em direção ao Leste. Ao olhar desses viajantes, trata-se do território do nonsense por excelência: a perplexidade ante os fatos ali observados, o assombro e a incompreensão ante o que se afigura, a um olhar estrangeiro e educado segundo os padrões rigorosos da civilização, como pertencente ao universo do fabuloso, desempenham também, a função de um discurso laudatório, às avessas, às conquistas do humanismo europeu. As comparações entre o "lá" e o "cá" estão na ordem do dia nesses relatos de viagem. Ao mesmo tempo, a aplicação de parâmetros que não fazem sentido na realidade avistada parte, invariavelmente, do pressuposto da superioridade da mentalidade moderna sobre os arcaísmos e as aberrações com que os viajantes se confrontam o tempo todo. 
A nova ordem que rege o pensamento e o discurso desses viajantes, construída sobre a ruptura radical com tudo o que possa estar associado à Idade Média e às suas heranças sociais e religiosas, uma ordem orgulhosa de si mesma e frequentemente arrogante, torna trágicos ou risíveis os costumes descritos: a infantilidade dos habitantes desse Leste aliena-os, também, do universo do Fortschritt, ao qual talvez eles, ingenuamente, anseiem por pertencer, mas do qual parecem, de antemão, excluídos pelo seu próprio condicionamento à realidade em que nasceram. E esse condicionamento, como acontece aos filhos de servos que são casados à força por seus senhores, parece destinado a perpetuar-se no tempo, condenando as suas vítimas à eterna repetição dos mesmos ciclos de vícios, isto é, fazendo com que suas histórias de aprisionamento se repitam, de maneira idêntica, de geração em geração.

O imobilismo, a ausência de sentido de ações equivocadas, a letargia, a passividade, a atuação de sentimentos obscuros, a negligência, a falta de disciplina são as atitudes que, ao olhar ocidental, empenhado na grande mobilização transformadora do século XIX, explicam o paradoxo da miséria absoluta em meio à abundância de recursos, ao mesmo tempo em que o engano, a superstição e as crenças sem fundamento se tornam objeto de intervenção e de transformação por meio de uma ação humana que tem como horizonte um novo absoluto: a objetividade científica e racional. É à luz desse absoluto, portanto, governado pela astúcia, que será avaliada a realidade humana nessa terra incognita, e à luz desse absoluto, também, se revelará, consistentemente, o seu absurdo.

O nonsense e o descomedimento são também características que Karl Emil Franzos destaca, de maneira recorrente, em suas narrativas e Kulturbilder, ao mesmo tempo em que aplica sobre o universo judaico de sua Barnow ficcional - que nada mais é do que a Czortkow galiciana em que veio ao mundo - e de todo o território judaico oriental os critérios de uma cultura modernizada. Face à própria radicalização dos conflitos em seu tempo, ele projeta sobre o setor judaico conservador todas aquelas características que, na mentalidade europeia da "civilização", estavam associadas ao universo da barbárie, da ignorância, da superstição e do obscurantismo: os aspectos irracionais da existência são, em sua obra, automaticamente assimilados à barbárie, ao avesso do bom-senso, que é a imagem cristalizada do Leste europeu no século XIX. 
O conflito entre ideologias, que marca o mundo retratado por Franzos, o Kulturkrieg no qual ele toma partido de maneira tão eloquente, é também o conflito central dos judeus da Galícia e Bucovina, divididos entre o crepúsculo de um universo que, havia séculos, lutava para manter-se fechado às influências externas e fiel às próprias raízes e a sedução de um mergulho na história e na modernidade que, com o avanço, sobre o Leste, do ideário iluminista e do modo de produção capitalista, tornava-se, a cada tanto, mais atraente e aparentemente confiável.

As fronteiras entre leste e oeste, cujos contornos Franzos desenha e redesenha, de maneira obsessiva, em seus textos, são fronteiras culturais e psicológicas mais do que nacionais ou geográficas. Os territórios ocupados por mentalidades que ele contrapõe reiteradamente interpenetram-se o tempo todo na medida em que ele percorre diferentes aspectos de sua Halb-Asien, buscando não chegar a termos de acordo, isto é, concebendo uma Mitteleuropa da conciliação e do entendimento, como o fizeram expoentes anteriores da Ghettoliteratur, e sim expô-la, à maneira do que faziam os viajantes do iluminismo na passagem do século XVIII para o XIX, ao menosprezo quando não abertamente ao escárnio.

\section{Referências bibliográficas}

ASCHHEIM, Steven. Brothers and Strangers - The East European Jew in German and German Jewish Consciousness, 1800-1923. Madison, The University of Wisconsin Press, 1982.

FRANZOS, Karl Emil. Vom Dur zur Donau. Berlim, Rütten \& Loening, 1970, p. 162. Idem. Moschko von Parma - Drei Erzählungen. Viena, Globus Verlag, 1972.

Idem. Aus Halb Asien. Berlim, J. G. Cottasche Buchhandlung, 1914.

Idem. Der Bart des Abraham Weinkäfer. Leipzig, Reclam, 1964.

Idem. Der Pojaz. Königstein, Athenäum, 1979.

Idem. Vom Don zur Donau. Berlim, Rütten \& Loening, 1970.

Idem. Ueber A. Bernstein in Allgemeine Zeitung des Judentums. 1895, Heft 1, p. 5

Idem. Leopold Kompert in Jahrbuch für jüdische Geschichte und Literatur. 1906, p. 147 Idem. Erzählungen aus Galizien. Berlim, Nicolai, 1993. 
FUCHS, Anne \& KROBB, Florian (Orgs). Ghetto Writing - Traditional and Eastern Jewry in German-Jewish Literature from Heine to Hilsenrath. Rochester, Camden House, 1999.

GLASENAPP, Gabrielle von. Aus der Judengasse - Zur Entstehung und Ausprägung deutschsprachiger Ghettoliteratur im 19. Jahrhundert. Tübingen, Max Niemeyer Verlag, 1996.

WOLFF, Larry. Inventing Eastern Europe - The map of civilization on the Mind of the Enlightenment. Stanford, Stanford University Press, 1994, p. 13. 